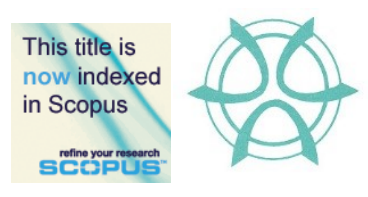

PLANNING MALAYSIA:

Journal of the Malaysian Institute of Planners

VOLUME 18 ISSUE 3 (2020), Page $71-81$

\title{
STAKEHOLDER MANAGEMENT OF CONSERVATION IN LOWER KINABATANGAN SABAH
}

\author{
Marcela Pimid $^{1}$, Normah Abdul Latip ${ }^{2}$, Azizan Marzuki ${ }^{3}$, Mohd \\ Umzarulazijo Umar ${ }^{4}$, and Kumara Thevan Krishnan ${ }^{5}$ \\ ${ }^{1,2,3,4}$ School of Housing, Building, and Planning \\ UNIVERSITI SAINS MALAYSIA \\ ${ }^{5}$ Faculty of Agro Based Industry \\ UNIVERSITI SAINS MALAYSIA
}

\begin{abstract}
Effective conservation measures are essential to protect nature and wildlife which act as flagship attraction for ecotourism to flourish. The study focuses on conservation management of natural forests and wildlife by multiple stakeholders in Lower Kinabatangan Sabah. Rare and endangered wildlife species is the main attraction for ecotourism development in this area. The study employed a mixed method research by integrating quantitative and qualitative approaches. Analyses revealed contradictory findings whereby local indigenous communities were unaware about progress of established Lower Kinabatangan Wildlife Sanctuary and thereby requested for enhancing current conservation management. However, other stakeholders reported that the sanctuary fulfilled its objectives. The study further proposed solutions to improve current conservation by considering the viewpoints of all stakeholders involved in conservation initiatives in the Lower Kinabatangan Sabah.
\end{abstract}

Keywords: Multiple stakeholders, Conservation, Kinabatangan Sabah, Mixed method research

${ }^{1}$ Corresponding author’s email: mohdjaki@usm.my 
Marcela Pimid, Normah Abdul Latip, Azizan Marzuki, Mohd Umzarulazijo Umar, and Kumara Thevan Krishnan

Stakeholder management of conservation in Lower Kinabatangan Sabah

\section{INTRODUCTION}

In general, conservation is defined as the protection and/or sustainable use of species or ecosystem to ensure their long-term survival and viability (Kothari et al., 2000). Borgström (2015, p.70) defines conservation as "a series of measures required to maintain or restore the natural habitats and the populations of species of wild fauna and flora at favorable conservation status." The World Commission on Environment and Development (1987, p.15) defines sustainable as "development which meets the needs of the present without compromising the ability of future generations to meet their own needs." In this regard, the conservation of natural resources is essential element of sustainable development. Furthermore, conservation provides several significances for sustainable development, namely ecosystem services, amenity and recreational values, and an opportunity to use them for socioeconomic benefits, as well as to maintain intergenerational equity (Coffey \& Major, 2005; Robert et al., 2005).

Developing countries establish protected areas in order to provide ecosystem protection, environmental and landscape conservation, including its roles in social and economic aspects (Somarriba-Chang \& Gunnarsdotter, 2012). For instance, protected areas provide multiple environmental services to human beings such as to control soil erosion, recycle nutrients, and act as a water catchment system (Somarriba-Chang \& Gunnarsdotter, 2012). More importantly, it is used for human occupancy in many developing countries, particularly local indigenous people (Coria \& Calfucura, 2012). This is because a protected area gives them a crucial protection, a sense of belonging and essential spaces to continually practice traditional activities that are now often impossible elsewhere (Ami \& Hamzah, 2013). Nevertheless, the establishment of protected area in developing countries does not guarantee the main objective of protecting nature (Ami \& Hamzah, 2013). Many cases relate failures in managing protected areas with social and economic conflicts due to local people being excluded from decision-making and management, including a reason that different groups have varying perspectives on using the same natural resources (Hussain et al., 2016).

\section{RESEARCH BACKGROUND}

The Lower Kinabatangan is located in Sabah state (east Peninsular Malaysia), with a GPS coordinate of $5.5884^{\circ} \mathrm{N}$ and $117.8460^{\circ} \mathrm{E}$. Sabah is a well-known state as 'the land below the wind.' There are 25 districts in Sabah including the Kinabatangan. The capital town and center of Sabah is Kota Kinabalu, but the biggest district in Sabah is the Kinabatangan with an approximate size of 600 hectares. The Kinabatangan district is divided into upper and lower Kinabatangan wherein the upper Kinabatangan is severely disrupted by excessive logging and land clearing for plantations (Agama et al., 2015). Meanwhile, the Lower Kinabatangan survives due to growing efforts on conservation. Sandakan is the nearest town from Kinabatangan whereby it is located approximately $68.9 \mathrm{~km}$ 
from Kinabatangan town, and $110 \mathrm{~km}$ from the Lower Kinabatangan (Ghasemi \& Hamzah, 2014; Goh, 2015). It takes around 50 minutes flight from Kota Kinabalu to go to Sandakan airport, and another 1 hour 50 minutes of drive to reach the Lower Kinabatangan. Alternatively, tourists can drive or rent a taxi for approximately six hours of drive from Kota Kinabalu to the Lower Kinabatangan (Goh, 2015).

The Lower Kinabatangan Sabah is an urgent priority for conservation because it contains large expanses of biodiversity species and threatened ecosystems such as virgin tropical rainforests, freshwater swamp forest, limestone outcrop, secondary dry land, and lakes (WWF, 2004). The forests in this area support 129 species of mammal, 314 species of birds, 101 species of reptiles, and 33 species of amphibians (Lackman-Ancrenaz \& Manokaran, 2008). Based on the red list species of International Union for Conservation of Nature (IUCN), many species are threatened such as Bornean elephant, Bornean orangutan, and proboscis monkey (Sha et al., 2008; Estes et al., 2012). The forests provide natural habitat for the wildlife, connect fragmented areas, and facilitate multiple ecological processes needed for the ecosystem to function. At present, many forests are fragmented and subjected to an extensive conversion to make ways for development and lucrative agricultural sectors (WWF, 2004; Estes et al., 2012). Likewise, both wildlife species and their habitats located inside and outside protected areas in the Lower Kinabatangan are at increasing risk of ongoing over-exploitation and habitat loss (Estes et al., 2012; Goossens \& Ambu, 2012).

Efforts to safeguard remaining forests has led to the establishment of Lower Kinabatangan Wildlife Sanctuary (LKWS) with an approximate size of 26 103 hectares in 2005 (Ancrenaz et al., 2007; Sabah Wildlife Department, 2017a). Besides the LKWS, there are other types of protected areas (Doney et al., 2009) such as mangrove forest reserves and commercial forest reserves. Sadly, important areas of unprotected forests are located outside the protected areas, on the Sabah state land or alienated land. According to the Sabah Land Ordinance (2010), an alienated land is a leased state land and thereby granted for specific purposes of development such as oil palm cultivation. The LKWS is a strategy applied to strengthen the conservation initiatives in this area. According to the Sabah Wildlife Department (2017a), there are three purposes of the LKWS, namely (1) to protect the environment, habitat, and natural ecological process in an undisturbed manner, (2) to ensure maintenance of valuable biodiversity, and (3) to carry out necessary actions to conserve rare and endangered species of flora and fauna, biotic, as well as sources of biodiversity genetic.

In addition, Wildlife Conservation Enactment 1997 is introduced by Sabah government which categorize three types of protected areas, namely wildlife hunting area, conservation area, and sanctuary (Sabah Wildlife Department, 2017a). The purpose of the conservation area is to provide fast and 
Marcela Pimid, Normah Abdul Latip, Azizan Marzuki, Mohd Umzarulazijo Umar, and Kumara Thevan Krishnan

Stakeholder management of conservation in Lower Kinabatangan Sabah

flexible protection of wildlife and habitats, whereas wildlife hunting area is intended for managing animal population through regulated hunting. The strongest category of conservation is the sanctuary which wholly protects flora and fauna in this area. Therefore, an admission to the LKWS as a totally protected area is prohibited except for an officer in charge of the sanctuary, possess a valid permit of conducting research or a visiting permit to enter any sanctuary area for public (Sabah Wildlife Department, 2017a).

\section{METHODOLOGY}

The study aims to evaluate the stakeholders' opinions on the management of conservation in the Lower Kinabatangan Sabah based on two objectives. First, the study examines stakeholders' views on established Lower Kinabatangan Wildlife Sanctuary (LKWS) based on four aspects, namely awareness, effectiveness, community involvement, and overall opinion on its progress. Second, it assesses stakeholders' opinions in improving the conservation in this area. Multiple stakeholders involved in this study were local indigenous communities, community leaders, local authority, non-government organizations (NGOs), private companies, local and private sector ecotourism. There were four villages in the Lower Kinabatangan Sabah known as Sukau, Batu Puteh, Bilit, and Abai, but the study chose Sukau and Batu Puteh villages as study sites. Both villages were chosen based on historical background, geographical and financial constraints. This was because both villages had well established ecotourism programs and most conservation activities started in these villages. In addition, both villages were well connected with pave and gravel roads compared to Bilit and Abai. Consequently, it reduced financial burden in conducting this research.

In order to fulfil the research objectives, this study applied concurrent mixed method approach by integrating quantitative and qualitative approaches. Quantitative data collection was carried out by distributing 404 questionnaire surveys to each house in Sukau and Batu Puteh villages. Demographically, the number of distributed questionnaires corresponded to the total houses $(\mathrm{N}=404$ houses) with a total of 1560 males and 1433 females stayed in both villages. The survey was conducted by requesting a leader from each house and in case he or she was unavailable, a researcher requested a representative of the house. Two local villagers were hired and trained to facilitate in distributing the surveys in both villages. The questionnaires were measured using a 5-point Likert scale and consisted of three sections, namely socio demographic of respondents, opinions on the LKWS, and suggestions to improve the management of conservation in the Lower Kinabatangan Sabah. Data obtained from the questionnaires were subjected to frequency analysis and analyzed using Statistical Packages for the Social Sciences (IBM SPSS version 22). Since the quantitative data was limited to frequency test, the current findings were discussed by comparing it with existing research in similar study area. 
Qualitative data collection was conducted using in-depth semi-structure interviews to community leaders, local authorities, NGOs, private companies, local and private sector ecotourism in both Sukau and Batu Puteh villages. A purposive sampling was employed to select key informants wherein the interviewees were chosen based on their expertise and experiences in conservation in the Lower Kinabatangan Sabah. A total of forty respondents of interview were selected which comprised eleven local authorities, eight private companies, three NGOs, thirteen ecotourism operators, and five community leaders. Qualitative data were analyzed using content analysis, specifically manifest analysis whereby a researcher "describes what the informants actually say, stays very close to the text, uses the words themselves, and describes the visible and obvious in the text" (Bengtsson, 2016, p.3). A triangulation method was applied by integrating quantitative findings with interviews, reviews on published reports and articles, and notes written during field sampling.

\section{RESULTS AND DISCUSSION}

\section{Sociodemographic of respondents}

The study collected 328 valid questionnaires out of 404 distributed surveys, which indicated $81 \%$ of response rate. Valid questionnaires meant they had been checked and clean from errors such as missing values and outliers. Out of 328 surveys, $60.7 \%$ of respondents were males whereas $39.3 \%$ were females. Most respondents $(75.9 \%$ ) were local Sungai known as 'River people,' while $24.1 \%$ of respondents were a mixed ethnic of Bugis, Kadazan Dusun, and Malay. In term of educational level, most respondents accomplished secondary school (59.2\%), followed by primary school $(21.6 \%)$, tertiary education $(10.1 \%)$ while other respondents did not attend school at all (9.1\%). Regarding job employment, 25.6 $\%$ of respondents engaged in subsistence livelihoods such as farmers, fishermen, and logging workers, $25.3 \%$ worked as in conservation sector, $14.3 \%$ established personal business, $6.1 \%$ worked as government staffs, $5.2 \%$ worked in ecotourism sector, while $23.5 \%$ of the respondents were not working at all. The results implied the Lower Kinabatangan was dominated by Sungai people and very few involved in ecotourism activities despite broad opportunities in ecotourism venture in this area.

Furthermore, in term of salary, $60.9 \%$ of respondents received monthly income below RM 1000, $26.6 \%$ of respondents received revenue above RM 1000 , whereas $12.5 \%$ did not have income. In comparison to guidelines of monthly house income of the Sabah state (Daily News, 2015), most respondents $(60.9 \%)$ were living below poverty level because their monthly income were less than RM 1050. Overall, for conservation purpose, only $25.3 \%$ of respondents worked in conservation sector which indicated low participation among the communities in this area. 
Marcela Pimid, Normah Abdul Latip, Azizan Marzuki, Mohd Umzarulazijo Umar, and Kumara Thevan Krishnan

Stakeholder management of conservation in Lower Kinabatangan Sabah

\section{Lower Kinabatangan Wildlife Sanctuary}

The opinions of local communities on the LKWS were sought in order to evaluate current management of LKWS (Figure 1). The results showed that most respondents slightly knew about agenda of the LKWS (50.9\%). They were unsure about its effectiveness to protect the biodiversity and wildlife in the Lower Kinabatangan (53.4\%), as well as they uncertain whether the local communities were involved in conservation activities (43.6\%). In addition, they recommended to improve the current management of LKWS (46\%).

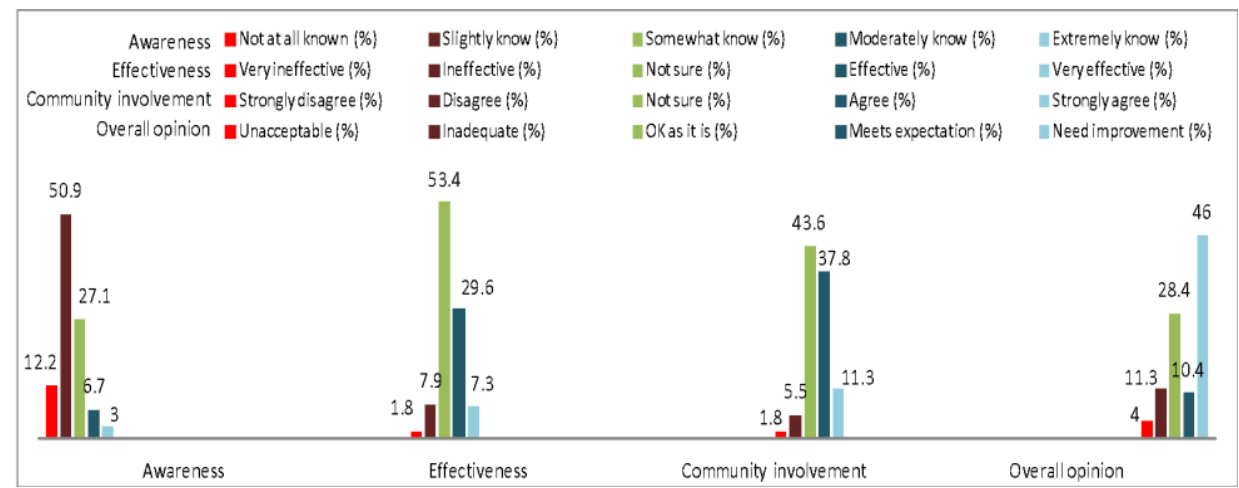

Figure 1: Respondents' opinions on current management of Lower Kinabatangan Wildlife Sanctuary.

Contrary to the questionnaire findings, key informants of qualitative interview explained that the LKWS focused on protecting endangered wildlife species in the Lower Kinabatangan and concurred that its objectives were achieved. In this view, manager of private lodge stated "last time, there were many forests here, but nowadays the forests have become smaller in size. I think if they really protect the wildlife, it should meet the objectives. So far, I think no new approach of sanctuary, but I know the authority continues to monitor the sanctuary and wildlife here." Likewise, owner of Balai Kito Homestay stated "the wildlife sanctuary ensures that the wildlife species and forests are well protected. I am not sure about other villages, but for Sukau village, yes, the objectives are met. It is because there are many wildlife species that are protected well since the initiation of the sanctuary."

The questionnaire findings indicated $46 \%$ of respondents stated that the current management of LKWS required improvement. Corresponding to the survey findings, a local authority reported that the objectives of LKWS subjected to continuous planning and monitoring: "Regarding the safety of wildlife species in their natural habitats, it is still ongoing. Many efforts are made to promote protected areas, or gazette any related areas for wildlife habitat and other purposes" (Deputy director of Wildlife Department). Another local authority 
highlighted that management plans for LKWS were incomplete and wildlife officers executed its functions at present: "If we talk about the progress of the Lower Kinabatangan Wildlife Sanctuary - whether we achieve the objectives or not, we need the timeline of management plan. Unfortunately, we have not finished outlining the management plans. For now, we execute the sanctuary's functions, such as to increase the wildlife corridor, carry out frequent monitoring, and replant trees along the riparian reserve" (Wildlife senior officer).

Contrary to the questionnaire findings, published reports revealed four positive impacts after the establishment of the LKWS (Sabah Wildlife Department, 2017a; Sabah Wildlife Department, 2017b). First, offenses which violated the Wildlife Conservation Enactment 1997 reduced. Second, illegal encroachments in the protected areas also reduced. Third, applications for licenses and permits for hunting according to the Wildlife Conservation Enactment 1997 increased. Finally, NGOs and estate companies contributed and participated in conservation efforts (Sabah Wildlife Department, 2017a; Sabah Wildlife Department, 2017b). When compared to the questionnaire findings, this result implied that the survey respondents were unaware about the LKWS performances particularly its management, progress, and effectiveness in protecting wildlife and habitats in the Lower Kinabatangan. Similarly, Hussin and Som (2008) reported that the views of local people in Sabah were seldom taken into a serious consideration when it came to a decision-making and implementation of policy in conservation aspect.

Previous studies showed that other stakeholders engaged in various activities to conserve the wildlife species and habitats in this area. For instances, WWF-Malaysia conducted capacity building and environmental education to promote conservation awareness among the local communities, whereas another NGOs known as HUTAN-KOCP carried out Kinabatangan Orangutan Conservation Project to protect the orangutan in the Lower Kinabatangan Sabah (Majail \& Webber, 2006; Latip et al., 2015a). The efforts undertaken by such organizations could improve conservation work in the Lower Kinabatangan, but all stakeholders involved in conservation activities need to mutually collaborate in order to enhance the management of LKWS (Latip et al., 2015b).

Based on the current findings, the management of LKWS could be improved by getting input from all stakeholders such as NGOs, community, private companies, local and private sector ecotourism in the Lower Kinabatangan, especially on how they could contribute positively towards achieving the goals of LKWS. More importantly, the local communities should be informed properly regarding the roles and progress of the sanctuary in their areas.

\section{Strategies to enhance conservation measures}

Five aspects of conservation were evaluated in order to improve the current conservation measures (Figure 2). Most respondents agreed that more financial 
Marcela Pimid, Normah Abdul Latip, Azizan Marzuki, Mohd Umzarulazijo Umar, and Kumara Thevan Krishnan

Stakeholder management of conservation in Lower Kinabatangan Sabah

aids should be allocated for conservation (44.2\%), more local communities should be trained to be self-independent to contribute positively in conservation, not merely attending a conservation awareness $(51.5 \%)$, their participation could be encouraged by offering monetary incentives $(41.8 \%)$, they should participate more in decision-making on conservation (52.4\%), and current rules of conserving wildlife and forest should be tightened (43.6\%). Furthermore, 28.7 $\%$ of respondents strongly agreed that the rules should be strengthened, indicating that the current rules were inadequate to prevent illegal hunting and deforestation. Notably, questionnaire respondents reported that illegal poaching was mostly committed by outsiders and suggested local authorities to enforce a strict penalty for offenders.

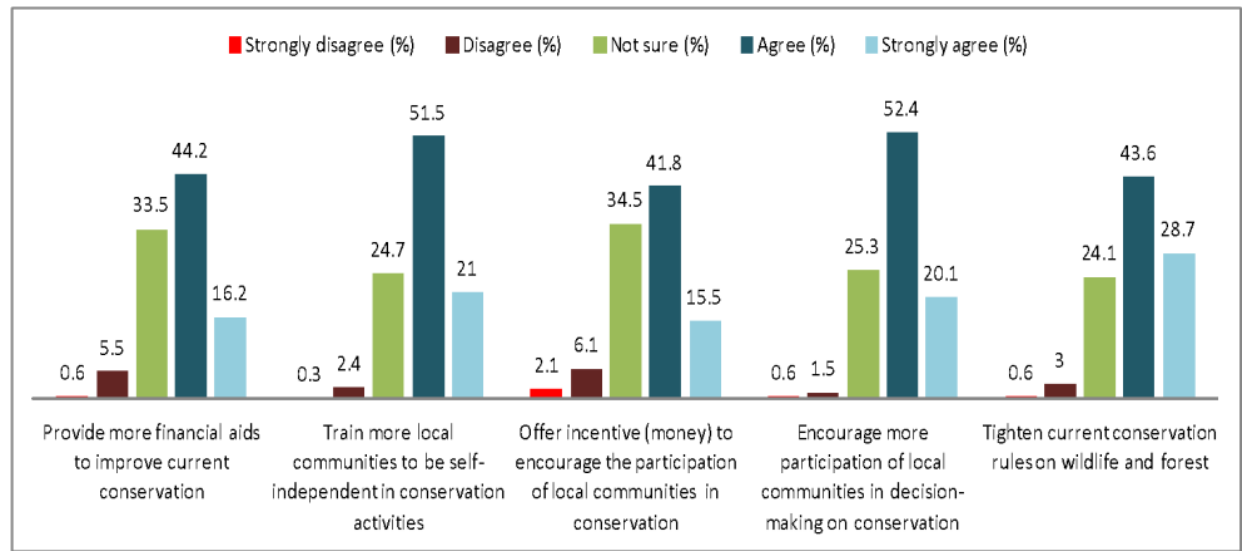

Figure 2: Respondents' opinions on future management of conservation in Lower Kinabatangan.

In comparison to the survey findings, key informants of interview revealed that it would be difficult to gazette other areas in the Lower Kinabatangan as sanctuary. At present, local authorities focused more on preserving the sanctuary and reconnecting fragmented areas between corridors: "Personally, I think it is difficult to gazette more areas, as the remaining areas are limited, but we are focusing more on preserving the one already being gazette, to try reconnecting fragmented areas and the corridors. The challenge is not all lands are reserved areas for conservation, other lands or lots belong to native lands or private owners. If they don't open their lands and remain as forest is okay, but if one day, they decide to open or sell it to other companies, it becomes a huge problem" (Wildlife senior officer).

In addition, extra efforts were made to request support from palm oil companies to make a passage enough for animals to pass through and build electrical fences along the route: "We request support from the palm oil companies to give us a route for wildlife to pass through and they build a territory 
using electrical fences along the route. The meaning of route is to a make a clear way for the wildlife to pass through without any restrictions. We are waiting for more plantation company to offer small area of their plantation for wildlife corridor" (Wildlife deputy officer).

Besides the suggestions provided by respondents of survey and interview, previous studies emphasized threat of increased illegal hunting activities, which were exacerbated in habitat fragments due to relative ease of accessing the forest in the Lower Kinabatangan (Latip et al., 2015b; Evans et al., 2016). Despite the establishment of LKWS since 2005, evidences showed illegal encroachment and hunting within the sanctuary (Evans et al., 2016). Therefore, significant effort must be invested to curb illegal activities so as to preserve rich wildlife species in this area.

\section{CONCLUSION}

Overall, both research objectives are fulfilled in understanding the stakeholder management on conservation of natural resources in Lower Kinabatangan Sabah. The natural resources especially rare wildlife species act as main attraction for ecotourism development in this area. Local government establishes the Lower Kinabatangan Wildlife Sanctuary in order to protect natural forests, flora, and fauna. However, the success of conservation highly depends on effective conservation management by various stakeholders in this area, including support and participation of local community. The results show conflicting findings whereby local communities are not aware about the progress of LKWS and propose to improve conservation measures, but other stakeholders state the objectives of LKWS are achieved. Therefore, recommendations are proposed by the stakeholders to improve the conservation measures in this area. Policy makers, academic institutional, government, and conservationists could apply the proposed strategies in improving conservation measures in rural areas which encounter similar conservation constraints.

\section{ACKNOWLEDGEMENT}

We acknowledge Universiti Sains Malaysia and Ministry of Education Malaysia for funding this project through Research University Grant, RUI (Grant No: 1001/PPBGN/8016051).

We extent our appreciation to all stakeholders involved in this study particularly the Sabah Wildlife Department, Sabah Forestry Department, District Office of Kinabatangan, and local communities from Sukau and Batu Puteh villages for their support and cooperation throughout the study. 
Marcela Pimid, Normah Abdul Latip, Azizan Marzuki, Mohd Umzarulazijo Umar, and Kumara Thevan Krishnan

Stakeholder management of conservation in Lower Kinabatangan Sabah

\section{REFERENCES}

Ancrenaz, M., Dabek, L., \& O’Neil, S. (2007). The costs of exclusion: recognizing a role for local communities in biodiversity conservation. PLoS Biology 5(11), e289.

Agama, A., Crowe, M., Hase, A. V., Kate, K. T., \& Lim, T. (2015). Policy and regulations assessment for implementing no net loss / net gain of biodiversity in sustainable multiple-use forest landscape, Sabah, Malaysia. Sabah Forestry Department: UNDP/GEF Project, pp 99.

Ami, J., \& Hamzah, A. (2013). Incorporating sacred places and traditional values in the management of protected areas for conservation and ecotourism. TEAM Journal of Hospitality and Tourism 10(1), 53-64.

Bengtsson, M. (2016). How to plan and perform a qualitative study using content analysis. NursingPlus Open 2, 8-14.

Borgström, S. (2015). Assessing the capacity of nature conservation law to help

biodiversity adapts to climate change: The case of Finland. Review of European, Comparative \& International Environmental Law 24(1), 69-82.

Coffey, B., \& Major, A. (2005). Towards more integrated natural resource management in Victoria: possible elements of an integrated state-wide policy framework. Australasian Journal of Environmental Management 12(sup1), 29-38.

Coria, J., \& Calfucura, E. (2012). Ecotourism and the development of indigenous communities: The good, the bad, and the ugly. Ecological Economics 73, 47-55.

Daily News (2015). Poverty level and ETP program, Accessed on May 19, 2015, pp 4.

Doney, S. C., Fabry, V. J., Feely, R. A., \& Kleypas, J. A. (2009). Ocean acidification: the other CO2 problem. Marine Science 1, 169-192.

Estes, J. G., Othman, N., Ismail, S., Ancrenaz, M., Goossens, B., Ambu, L. N., \& Palmiotto, P. A. (2012). Quantity and configuration of available elephant habitat and related conservation concerns in the Lower Kinabatangan floodplain of Sabah, Malaysia. PloS One 7(10), e44601.

Evans M. N., Vickers, S. H., Abu-Bakar, M. S., \& Goossens, B. (2016). Small Carnivores of the Lower Kinabatangan Wildlife Sanctuary, Sabah, Borneo, including a new locality for the Otter Civet Cynogale bennettii. Small Carnivore Conservation 54, 26-38.

Kothari, A., Pathak, N., \& Vania, F. (2000). Where communities care: community-based wildlife and ecosystem management in South Asia. International Institute for Environment and Development, pp 222.

Ghasemi, M., \& Hamzah, A. (2014). An investigation of the appropriateness of tourism development paradigm in rural areas from main tourism stakeholders' point of view. Fifth Asia Euro Conference. Procedia-Social and Behavioral Sciences 144, 15-24.

Goh, H. C. (2015). Nature and community-based tourism (CBT) for poverty alleviation: a case study of Lower Kinabatangan, East Malaysia. Malaysian Journal of Society and Space 11(3), 42-52.

Goossens, B., \& Ambu, L. N. (2012). Sabah Wildlife Department and 10 years of research: towards a better conservation of Sabah's wildlife. Journal of Oil Palm \& the Environment 3, 38-51.

Hussain, A., Dasgupta, S., \& Bargali, H. S. (2016). Conservation perceptions and attitudes of semi-nomadic pastoralist towards relocation and biodiversity 
management: a case study of Van Gujjars residing in and around Corbett Tiger Reserve, India. Environment, Development and Sustainability 18(1), 57-72.

Hussin, R., \& Som, A. P. M. (2008). Ecotourism, conservation programme, and local community participation: conflict of interests in Sukau village of Sabah, Malaysia. Sosiohumanika 1(1), 115-140.

Lackman-Ancrenaz I, \& Manokaran K. (2008). Kinabatangan biosphere reserve nomination Dossier. HUTAN.

Latip, N. A., Marzuki, A., Marcela, P., \& Umar, M. U. (2015a). Indigenous people, conservation and sustainable tourism at Lower Kinabatangan, Sabah: SWOT analysis. Australian Journal of Basic and Applied Sciences 9(7), 331-334.

Latip, N. A., Marzuki, A., Marcela, P., \& Umar, M. U. (2015b). The involvement of indigenous peoples in promoting conservation and sustainable tourism at Lower Kinabatangan Sabah: common issues and challenges. Australian Journal of Basic and Applied Science 9(7), 323-325.

Majail, J. \& Webber, D.A. (2006). Human dimension in conservation works in the Lower Kinabatangan: sharing PFW"s experience. Fourth Sabah-Sarawak Environmental Convention, pp 9.

Robert, K. W., Parris, T. M., \& Leiserowitz, A. A. (2005). What is sustainable development? Goals, indicators, values, and practice. Environment: Science and Policy for Sustainable Development 47(3), 8-21.

Sabah Land Ordinance (2010). State of Sabah Land Ordinance (Sabah Cap. 68). Land Ordinance.

Sabah Wildlife Department (2017a). Lower Kinabatangan Wildlife Sanctuary: Purposes, protected species, and locations. Reports by the Sabah Wildlife Department, Kinabatangan office, $\mathrm{pp} 7$.

Sabah Wildlife Department (2017b). Management and conservation: protected areas. Accessed $\quad 12 \quad$ April 2017 http://www.wildlife.sabah.gov.my/?q=en/content/protected-areas.

Sha, J. C. M, Henry B., \& Nathan S. (2008). Status and conservation of proboscis monkeys (Nasalis larvatus) in Sabah, East Malaysia. Primate Conservation 23, 107-120.

Somarriba-Chang, M. d. 1. A., \& Gunnarsdotter, Y. (2012). Local community participation in ecotourism and conservation issues in two nature reserves in Nicaragua. Journal of Sustainable Tourism 20(8), 1025-1043.

World Commission on Environment and Development. (1987). Our common

future. World Commission on Environment and Development (WCED). New York: Oxford University Press, pp 8.

WWF (2004). Poverty and conservation: ecotourism in the Lower Kinabatangan, Sabah, pp 2.

Received: January 2020. Accepted: $20^{\text {th }}$ May 2020 